Review

\title{
Myocardial Ischemic Syndromes, Heart Failure Syndromes, Electrocardiographic Abnormalities, Arrhythmic Syndromes and Angiographic Diagnosis of Coronary Artery Spasm: Literature Review
}

\author{
Ming-Yow Hung ${ }^{1,2,3}{ }^{\bowtie}$, Nicholas G. Kounis ${ }^{4}$, Meng-Ying Lu ${ }^{1}$, and Patrick Hu ${ }^{5,6}$ \\ 1. Division of Cardiology, Department of Internal Medicine, Shuang Ho Hospital, Taipei Medical University, New Taipei City, Taiwan \\ 2. Taipei Heart Institute, Taipei Medical University, Taipei, Taiwan \\ 3. Division of Cardiology, Department of Internal Medicine, School of Medicine, College of Medicine, Taipei Medical University, Taipei, Taiwan \\ 4. Department of Cardiology, University of Patras Medical School, Rion, Patras, Achaia, Greece \\ 5. University of California, Riverside, Riverside, California, USA \\ 6. Department of Cardiology, Riverside Medical Clinic, Riverside, California, USA
}

$\square$ Corresponding author: Ming-Yow Hung, MD, Division of Cardiology, Department of Internal Medicine, Shuang Ho Hospital, Taipei Medical University, New Taipei City, No.291, Zhongzheng Rd., Zhonghe District, New Taipei City, 23561, Taiwan. Tel: +886-2-22490088 ext 2714; Fax: +886-2-82733736; e-mail: myhung6@ms77.hinet.net

(1) The author(s). This is an open access article distributed under the terms of the Creative Commons Attribution License (https://creativecommons.org/licenses/by/4.0/). See http://ivyspring.com/terms for full terms and conditions.

Received: 2019.12.29; Accepted: 2020.03.23; Published: 2020.04.27

\begin{abstract}
In coronary artery spasm (CAS), an excess coronary vasoconstriction causing total or subtotal vessel occlusion could lead to syncope, heart failure syndromes, arrhythmic syndromes, and myocardial ischemic syndromes including asymptomatic myocardial ischemia, stable and unstable angina, acute myocardial infarction, and sudden cardiac death. Although the clinical significance of CAS has been underrated because of the frequent absence of symptoms, affected patients appear to be at higher risk of syncope, serious arrhythmias, and sudden death than those with classic Heberden's angina pectoris. Therefore, a prompt diagnosis has important therapeutic implications, and is needed to avoid CAS-related complications. While a definitive diagnosis is based mainly on coronary angiography and provocative testing, clinical features may help guide decision-making. We perform a literature review to assess the past and current state of knowledge regarding the clinical features, electrocardiographic abnormalities and angiographic diagnosis of CAS, while a discussion of mechanisms is beyond the scope of this review.
\end{abstract}

Key words: myocardial ischemic syndrome, heart failure syndrome, arrhythmic syndrome, provocative testing, coronary artery spasm

\section{Introduction}

Angina pectoris is caused by a transient imbalance between myocardial demand and supply $[1,2]$, which results in 2 types of ischemia, non-exertional supply ischemia and exertional demand ischemia [3]. Furthermore, coronary lesions are dynamic [4]. As a result, non-obstructive coronary lesions might restrict increases in coronary blood supply if vascular tone is augmented [4], and hence myocardial ischemia is not always preceded by increased oxygen demand [5]. Among the mechanisms of angina pectoris, coronary artery spasm (CAS) had long been considered the chief one [6], albeit as yet unproved until 1940s when the recognition of angina-associated fixed atherosclerotic obstruction post mortem led to a revision of the theory that CAS may produce paroxysmal myocardial ischemia [7-9] (Table 1).

However, Dr. Myron Prinzmetal (1908-1987) published his observations on "A variant form of angina pectoris" in 1959 , which was the $1^{\text {st }}$ article [10] 
distinguishing it as a distinct entity from the classic angina pectoris (pectoris dolor) described by Dr. William Heberden (1710-1801) based on 20 cases with this affliction in 1772 [11], which occurred when increased cardiac work or emotional disturbance provoked chest pain and was relieved by rest or the administration of nitroglycerin. Although some patients with non-exertional angina of Heberden's cases probably represents the $1^{\text {st }}$ reported variant form of angina pectoris, his description of non-exertional angina is vague. On the other hand, patients with Heberden's angina may also manifest CAS [12].

In Prinzmetal's $1^{\text {st }}$ report of 32 cases of variant angina, of which 20 were personally observed and 12 were from the literature, the pain associated with transient non-progressive ST-segment elevation appeared at rest or during ordinary activity but was not brought on by exercise or emotional disturbance. Among the 32 patients studied, 12 developed myocardial infarction during follow-up [10]. Because coronary atherosclerosis was a common finding in both forms of angina pectoris post mortem, and the attack usually occurred with the subject at rest, when vascular hypertonic activity is physiologically greatest [10], vascular hypertonus proposed by Prinzmetal et al. or CAS proposed by other researchers was the explanation for variant angina. Although CAS had never been proved $[7,13]$ within a decade following the $1^{\text {st }}$ report of coronary angiography in 1959 [14], CAS was documented angiographically in early 1970s in patients of variant angina $[13,15,16]$.

In the 1970s and 1980s, the diagnosis of CAS by coronary angiography in the catheterization laboratory was not rare. It then became clear that CAS could occur in patient with atherosclerotic obstructive coronary artery disease [10,11] or angiographically normal coronary arteries, which was referred to as "variant of the variant" [15] or "coronary vasospastic angina" [17]. Moreover, ST-segment depression rather than non-progressive elevation occurred more commonly in CAS [18, 19]. Therefore, the term "variant angina" is used for CAS-related angina with transient non-progressive ST-segment elevation. Additionally, CAS and acute coronary events can be caused by allergic reactions, with mediators released during mast cell degranution such as histamine, chymase, leukotrienes, platelet activating factor acting on coronary vascular smooth muscle cells that constitute the pathophysiologic basis of Kounis syndrome [20, 21]. Collectively, the presence of atherosclerotic obstructive coronary artery disease cannot be considered as the only determinant of angina pectoris [22].
Table 1. Evolution of clinical Importance of CAS.

\begin{tabular}{ll}
\hline Year & Event \\
\hline 17th & Edward Hyde (1609-1674), a nonmedical writer and historian, describes \\
century & his father's ailment as the $1^{\text {st }}$ case of chest pain syndrome, which is very \\
suggestive of angina pectoris, along with complete follow-up on the \\
disease until his father's sudden death in 1632, in his biography, Life of \\
Edward, Earl of Clarendon [138]. \\
The 1st account of classic angina pectoris is described by William Heberden \\
(1710-1801) [11]. It has 8 characteristics [138], \\
The access and the recess of the fit is sudden. \\
There are long intervals of perfect health. \\
Wine, and spirituous liquors, and opium afford considerable relief. \\
It is increased by disturbance of the mind \\
It continues many years without any other injury to the health. \\
In the beginning it is not brought on by riding on horseback, as in a \\
carriage, as is usual in diseases arising from scirrhus or inflammation. \\
During the fit the pulse is not quickened \\
Its attacks are often after the 1 st sleep, which is a circumstance common to \\
many spasmodic disorders
\end{tabular}

1895 The $1^{\text {st }}$ practical electrocardiography is invented by Dr. Willem Einthoven [139].

1940 Among the mechanisms of angina pectoris, although CAS has long been considered the chief one [6], the difficulty of visualizing CAS of the arteriosclerotic arteries in patients with angina pectoris is frequently pointed out [7].

1941 While the theory that CAS may produce paroxysmal myocardial ischemia is as yet unproved, the recognition of angina-related fixed atherosclerotic obstruction post mortem in 1940s leads to a revised perception that atherosclerosis, rather than CAS, is the chef mechanism of angina pectoris. Furthermore, every patient suffering primarily from angina pectoris without evidence of valvular disease or hypertension has shown old complete occlusion of $\geq 1$ major coronary artery post mortem [8].

1959 Classic Heberden's angina has 2 major features [2],

provoked pain by increased work of the heart or disturbance of the mind is relieved by rest or the administration of nitroglycerin

an electrocardiography taken during pain shows ST-segment depression in leads I, II, III and V4, without reciprocal elevation

1959 "A variant form of angina pectoris" described by Dr. Myron Prinzmetal [2] has 2 major features,

pain at rest or during ordinary activity, but not by effort, is relieved by the administration of nitroglycerin

ST-segment elevation with reciprocal ST-segment depression

1959 An experimental intermittent occlusion of a large epicardial coronary artery in 25 dogs performed by Prinzmetal et al. [10] reproduced chest pain and electrocardiographic abnormalities of variant angina, including arrhythmias and non-progressive ST segment elevation in the corresponding leads [10]. These changes disappeared and reappeared repeatedly by loosening and tightening the ligature, suggesting that hypertonus of a diseased vessel is probably causing this syndrome. Interestingly, the area of ischemia due to CAS demonstrates systolic ballooning [10].

1962 An occasional angiographic documentation of CAS in a patient with angina and normal electrocardiography at rest is reported [103].

1963 Ergonovine, an ergot alkaloid used to control postpartum uterine bleeding, was found in 1949 to provoke angina, and was proposed in 1963 as a diagnostic test for coronary disease [105].

1972 Contrast-induced CAS, which reproduces chest pain, is demonstrated angiographically in a patient with Prinzmetal angina [85].

1972 The 1st provocative testing using intravenous ergonovine is performed by the Cleveland Clinic [101].

1974 Yasue et al. reports the use of subcutaneous injection of methacholine in provoked CAS [105].

1978 CAS is associated with variable threshold exertional angina [23, 41].

1987 The $1^{\text {st }}$ provocative testing using intracoronary ergonovine is performed by Hackett et al. [104].

1988 The 1st provocative testing using intracoronary acetylcholine is performed by Okumura et al. [106].

1992 Risk factors for CAS were not known until a U.S. study in 1992 demonstrated that smoking was a risk factor for CAS in young women [140].

1993 Smoking is a major risk factor for Japanese CAS patients [141].

2000 CAS-related regional wall motion abnormality, left ventricular dilation and reduced ejection fraction improve 6 months to $>1$ year after medical treatment, including calcium channel blockers and nitrate/nicorandil [50, 53].

2005 C-reactive protein level is an independent risk factor of CAS in Taiwanese patients [142].

CAS $=$ coronary artery spasm 


\section{Prevalence}

CAS-related angina and myocardial ischemia, regardless of symptoms, are common [10, 23], though not nearly as common as classic Heberden's angina pectoris. The prevalence of CAS and obstructive coronary artery disease in Taiwanese general population during a follow-up period of 12 years is $0.067 \%$ and $8.7 \%$, respectively [24]. However, the prevalence of CAS in different general populations remains to be defined. On the other hand, the number of CAS patients would rise among angina patients when systematic rules for its detection are applied [23]. Therefore, undoubtedly the incidence of CAS-related myocardial ischemia could be significantly greater than is indicated by the demonstration of variant angina if one considers that (1) angina at rest with S-T segment depression and with pseudonormalization of $\mathrm{T}$ waves also appears to be caused by CAS; (2) that asymptomatic ischemic episodes are frequent [23, 25]; and (3) that cold-induced angina may result from CAS [26].

There are wide differences in the CAS prevalence in different countries. The frequency of CAS in Japan is greater than that in western countries [27] and the diagnosis of variant angina with transient non-progressive ST-segment elevation among patients with angina referred to Japanese medical institutions is as high as $40 \%$ [17]. In addition, multiple spasms ( $\geq 2$ spastic coronary arteries) induced by provocative testing in Japanese $(24.3 \%)$ [28] and Taiwanese populations (19.3\%) [29] occur more frequently than in Caucasians (7.5\%) [30]. CAS is more prevalent among men than women in East Asia as well as Western countries [17, 29]. Most CAS occur in patients between 40 and 70 years of age and the prevalence decreases after 70 years of age $[10,17$, 29]. Previous Asian and German studies have shown that the prevalence of CAS is around $50 \%$ in patients with angina and $57 \%$ in Asian patients with acute coronary syndrome without obstructive coronary artery disease [31-33]. Among provocative vasomotor studies in patients with acute coronary syndrome without a culprit lesion, $79 \%$ of Japanese patients had a positive result [34], whereas $16 \%$ of French [35] and $49 \%$ of similar German [33] patients developed CAS after intracoronary acetylcholine. On the other hand, CAS can be difficult to diagnose owing to premedication with spasmolytic drugs such as nitroglycerin or calcium channel blockers, avoidance of coronary constrictors, and variation of disease activity. The prevalence of CAS tends currently to decrease, especially in Japan, for many reasons such as less performing vasoreactivity test (time consuming), or widespread use of statins and calcium channel blockers [36]. Taken together, these results suggest that while racial differences exist in coronary vasomotor response [27], CAS prevalence in different populations is as yet unknown.

\section{Myocardial Ischemic Syndromes with or without Symptoms}

Symptoms vary widely and may be silent (Table 2), among which the length (longer duration) of CAS is an essential determinant. The typical CAS-related angina at rest is a vague sensation of compression in the precordium or upper abdomen [17] with radiation to the neck, jaws, left shoulder, and elsewhere [17]. The angina may be accompanied by cold sweats and disturbance of consciousness including syncope [17]. During CAS attack, a lowering of blood pressure or decrease in pulse pressure may appear [10]. Although prolonged episodes of CAS can lead to angina and even myocardial infarction [37], brief episodes of CAS without any symptoms can result in silent myocardial ischemia, or cause life-threatening arrhythmias, resulting in sudden death [38-39]. The incidence of silent myocardial ischemia is more than 2 times higher than that of symptomatic ischemia [38]. Hence, there is a wide spectrum of CAS-related myocardial ischemic syndromes, including silent myocardial ischemia, stable angina, unstable angina, acute myocardial infarction and sudden death $[23,37,38$, 40]. In addition, CAS has been reported to be associated with migraine syndrome [41], Raynaud's phenomenon [41] and spasm of digital arteries [42].

CAS occurs mostly at rest or at night, sometimes in association with awakening from sleep [43], especially from midnight to early morning [10, 23, $38-40,44-46]$, during which $67 \%$ of CAS attacks are asymptomatic [17]. A previous report using intravenous methergine provocation tests showed that the frequency of CAS was 38\% when angina occurred only at rest, compared with $13.8 \%$ when angina at rest and during exertion [30]. Moreover, CAS precipitated by variable threshold effort, particularly in the morning in some patients [39], can be associated with ST-segment depression or elevation, or pseudonormalization of $\mathrm{T}$ waves $[18,23]$, suggesting that spastic arteries are abnormal because normal coronary arteries dilate during exercise.

The incidence of CAS shows daily, weekly, monthly, and circadian variations [47]. The complexity of the neural networks modulating the tone of the coronary arteries [48], and the association of the occurrence of CAS in the early morning with rapid eye movement [49], during which time there is a rapid elevation of sympathetic activity, suggest that changes in the activity of the autonomic nervous system may be involved in the circadian variation of CAS. With the use of coronary artery angiography in 
patients with CAS, Yasue at al. [46] found that in the early morning, the tone of the major coronary artery was increased and its diameter was smaller than normal, while in the afternoon, the major coronary artery was usually dilated. Therefore, most patients with CAS have a diurnal variation in the exercise capacity. Of note, as attacks of CAS may occur frequently, ie, several times every day, or may not occur for several months to several years [17], patients should be followed up closely.

\section{Heart Failure Syndromes}

CAS, especially multiple spasms [50], causes myocardial necrosis (a form of reperfusion injury) [51], which leads to a reduction in diastolic compliance during angina [52] and heart failure with reduced ejection fraction (HFrEF) [50, 53-56] (Table 2). It has been shown that the left ventricular dysfunction may return in about 2 minutes to basal levels as the electrocardiographic changes start reverting to the pre-CAS state [22, 57]. On the other hand, about $30-47.6 \%$ of hospitalized patients with optimally treated HFrEF $<45 \%$ has provoked CAS [50, 53-55]. While the prevalence of hypertension and smoking was higher in CAS-related than non-CAS-related HFrEF in a previous study [55], further studies are needed to identify the risk factors of CAS-related HFrEF. The CAS-related regional wall motion abnormality, left ventricular dilation and reduced ejection fraction improve 6 months to $>1$ year after medical treatment for CAS, including calcium channel blockers and nitrate/nicorandil [50,53]. HFrEF, such as dilated cardiomyopathy in Syrian hamsters [51,58] and in German patients [59], with microcirculatory disorders which is possibly due to CAS, can be improved by treatment with verapamil and diltiazem, respectively, through vasodilator effect. Notably, while adjunctive diltiazem treatment in possibly CAS-related dilated cardiomyopathy has beneficial effects on mortality, hemodynamics and symptoms through reducing afterload, decreasing arrhythmias, and inhibiting catecholamines [59], diltiazem in patients with $\mathrm{HFrEF}$ due to infarction has a poor outcome [60]. On the other hand, the use of calcium channel blockers in patients with non-ischemic HFrEF is not a first-line therapy at the present time. Therefore, although 1st generation dihydropyridine and nondihydropyridine calcium channel blockers (except amlodipine and felodipine) should generally be avoided in patients with non-CAS-related HFrEF since they provide no functional or mortality benefit and may worsen outcomes [61], if patients with HFrEF have provoked CAS, the use of calcium channel blockers might be beneficial to improve CAS-related myocardial ischemia [50, 54]. Future studies are required to elucidate the potential treatment role of calcium channel blockers in CAS-related HFrEF. On the contrary, the use of $\beta$-blockers in patients with CAS and HFrEF may result in the aggravation of CAS [56].

Table 2. Clinical characteristics and electrocardiographic abnormalities of CAS.

\begin{tabular}{|c|c|c|}
\hline Symptoms & Signs & Electrocardiography \\
\hline $\begin{array}{l}\text { Chest pain, oppressive or stabbing } \\
\text { [114], with radiation at rest, at night, } \\
\text { during sleep [13, 43], during ordinary } \\
\text { activity, or when awakening in the } \\
\text { morning [43] }\end{array}$ & Hypotension $[10,13,57,65]$ & $\begin{array}{l}\text { ST-segment depression without reciprocal change [63] } \\
\text { Widespread: diffuse but less severe CAS [22] } \\
\text { Isolated in the anteroseptal and anterior leads: CAS of a diagonal or septal branch [22] }\end{array}$ \\
\hline $\begin{array}{l}\text { Waking up from sleep with chest pain } \\
\text { [13] }\end{array}$ & $\begin{array}{l}\text { Bradycardia (more frequent than } \\
\text { tachycardia }[43,57]\end{array}$ & ST-segment elevation with reciprocal ST-segment depression \\
\hline $\begin{array}{l}\text { Variable threshold exertional chest pain } \\
\text { [41] }\end{array}$ & $\begin{array}{l}\text { Tachycardia (less frequent than } \\
\text { bradycardia) [22] }\end{array}$ & T wave change (inversion, peaking) $[22,23]$ \\
\hline Dyspnea $[13,50]$ & $\begin{array}{l}\text { Reversible regional wall motion } \\
\text { abnormality, reversible left ventricular } \\
\text { dilation, reversible heart failure with } \\
\text { reduced ejection fraction }[50,53-56]\end{array}$ & $\begin{array}{l}\text { Peaking T wave followed by ST-segment elevation due to } 100 \% \text { CAS-induced occlusion } \\
\text { [22] }\end{array}$ \\
\hline Cold sweats $[13,17]$ & $\begin{array}{l}\text { Dilated cardiomyopathy with atrial } \\
\text { fibrillation [54] }\end{array}$ & Pseudonormalization of ST-segment and T-wave [10] \\
\hline Nausea [13] & $\begin{array}{l}\text { Transient left ventricular wall motion } \\
\text { abnormality [143] }\end{array}$ & Taller and broader $R$ wave or disappearance of $R$ wave $[10,65]$ \\
\hline Dizziness [13] & $\begin{array}{l}\text { Arrhythmia with or without angina }[10, \\
43,83]\end{array}$ & $\begin{array}{l}\text { Arrhythmias, mostly ventricular, include sinus tachycardia, sinus bradycardia, sinus } \\
\text { arrest with or without junctional escape beats, atrial premature complex, paroxysmal } \\
\text { atrial tachycardia, paroxysmal atrial fibrillation }[42], 1^{\text {st }} \text { degree atrioventricular block } \\
\text { [13], } 2^{\text {nd }} \text { degree (Mobitz I and II) atrioventricular block }[13,70], 3^{\text {rd }} \text { degree complete } \\
\text { atrioventricular block [13], } \\
\text { ventricular premature complex, ventricular bigeminy, ventricular tachycardia, pulseless } \\
\text { electrical activity and asystole }\end{array}$ \\
\hline Syncope $[17,83]$ & Spasm of digital arteries [42] & $\begin{array}{l}\text { ventricular fibrillation, including those episodes which revert spontaneously [84], and } \\
\text { which require electrical defibrillation }\end{array}$ \\
\hline Palpitation [43] & & $\begin{array}{l}\text { Left bundle branch block, incomplete or complete }[11,12,42,77] \\
\text { Right bundle branch block [76] } \\
\text { Decreased S wave magnitude [47] } \\
\text { Negative U wave [47] }\end{array}$ \\
\hline
\end{tabular}


In addition, the prevalence of atrial fibrillation in the patients with dilated cardiomyopathy and CAS is greater than that in dilated cardiomyopathy without CAS $[67 \%$ vs $8 \% \quad(\mathrm{P}<0.05)]$ [54]. Hence, dilated cardiomyopathy with atrial fibrillation may be a clue for identifying CAS [54]. Taken together, although there is no guideline addressing the role of calcium channel blockers in CAS-related heart failure [55], CAS should be considered in the differential diagnosis of dilated cardiomyopathy or HFrEF as calcium channel blockers may be a promising therapy $[53,55]$, and provocative tests for CAS can be safely performed after the stabilization of heart failure [56].

\section{Electrocardiographic Abnormalities and Arrhythmic Syndromes}

All CAS-related electrocardiographic changes may occur without the subsequent angina [22] (Table 2 ), as angina develops in only $20-30 \%$ of episodes of ischemic ST-segment changes [17]. There is a great variability of the electrocardiographic changes in the same patient during different CAS episodes [22], because CAS may occlude $\geq 1$ vessel and may diffusely involve smaller arterial branches, resulting in myocardial ischemia with ST-segment elevation or depression or with only $\mathrm{T}$ wave changes [23]. Occasionally, the ST-segment changes during CAS may seem to improve a previously depressed ST-segment [10, 47]. In Prinzmetal's original report, spurious improvement of the prior low $\mathrm{T}$ wave during angina was noted [10]. It has been demonstrated that the pseudonormalization of $\mathrm{T}$ waves, initially described in 1970s when continuous electrocardiographic recordings became available [62], is directly related to transmural myocardial ischemia in CAS [23]. Therefore, an electrocardiography showing "improvement", or pseudonormalization, of ST-segment and $\mathrm{T}$ wave changes should be studied carefully for this may be the only graphic change of CAS [10].

On the other hand, a normal electrocardiography does not rule out the presence of CAS [10], as it may be recorded when the CAS starts early or when the CAS is only mild [47]. CAS of a major coronary artery results in ST-segment elevation in the leads corresponding to the distribution of a large coronary artery and the subsequent locations of myocardial infarction [10]. Of note, thallium scintigraphy revealed a regional massive and localized reduction of myocardial perfusion during S-T segment elevation and pseudonormalization of $\mathrm{T}$ waves [23]. While a transmural ischemia and injury results in ST-segment elevation, peaking of $\mathrm{T}$ waves, or pseudonormalization of $\mathrm{T}$ wave changes, a less severe, non-transmural subendocardial myocardial ischemia results in ST-segment depression or T wave inversion [22]. Notably, CAS is associated more frequently with ST-segment depression rather than ST-segment elevation $[18,19,63]$. ST-segment depression appears when CAS of a major artery is less severe, when a major artery receiving collaterals is completely occluded, or when a small artery is completely occluded [64]. This condition may exist in unstable angina/non-ST-elevation myocardial infarction. About $45 \%$ of patients with angina at rest and ST-segment depression alone has CAS [30]. Moreover, ischemic episodes characterized by ST-segment elevation or depression or by $\mathrm{T}$ wave change (inversion, peaking, pseudonormalization of negative wave) may occur in the same patient with CAS within a few minutes $[22,23]$. In addition to ST-segment changes, a taller and broader $R$ wave [10, 65], a decrease in magnitude of $S$ wave, peak $T$ wave and negative $U$ wave may also appear [47]. Because the location of CAS may be fixed, or fluctuate from one vessel to another over time [66], ST-segment elevation and depression could occur alternatively in the same patient or even in the same lead within minutes or hours [23]. Furthermore, electrocardiographic changes may vary during repeated provocative tests and recurrent spontaneous attacks $[67,68]$. Hence, the appearance of ST-segment changes may differ over time.

The ST-segment and T wave changes of CAS are associated with the subsequent left ventricular dysfunction and practically every known form of arrhythmia [10, 32, 47, 69-73], sometimes life-threatening $[22,58]$, which often occur in patients with acute coronary syndrome [32]. The high incidence of arrhythmia in CAS may be related to the usually severe ischemia or to the sudden massive reperfusion [69]. Among arrhythmias, ventricular premature complex was most common and high-grade atrioventricular block was next most common [11], and of special importance are sinus node arrest and ventricular fibrillation (VF) [69]. Bradycardia and supra-His conduction disorders tend to occur preferentially during inferior wall ischemia, usually indicating the most commonly CAS-involved right coronary artery, given the junctional location of the block due to ischemia of the branch supplying the sinoarterial and atrioventricular node [74], while an infra-His block may occur when CAS involves left coronary arteries [75]. As a result, sinus bradycardia occurs more frequently than sinus tachycardia, and when profound sinus bradycardia and periods of sinoarterial block or sinus arrest occur, it may cause an acute form of the sick sinus syndrome complicated by syncope [69]. In addition, right bundle branch block [76] and intermittent left bundle branch block 
$[11,12,43,77]$ have been reported to be associated with CAS. CAS-related sudden death most frequently results from bradyarrhythmias, rather than from tachyarrhythmias [78, 79]. Nitrates and calcium channel blockers may be effective in the control of CAS induced arrhythmia, but other traditional antiarrhythmic agents and pacemaker treatment may be required in some patients [69].

Arrhythmias, particularly ventricular, appear more frequently through unknown mechanisms during CAS attacks in $>50 \%$ of cases than during attacks of classic Heberden's angina pectoris [10, 43] (Table 2). Ventricular arrhythmias are more common during anterior wall ischemia [74]. Sudden death with normal appearing coronary arteries on autopsy examination has been attributed to VF complicating CAS [80]. Although VF uisually needs to be terminated by cardioversion [30], CAS-related VF rarely reverts spontaneously [81-83]. In addition, VF was found to be asymptomatic in $43 \%$ and nonsustained in $40 \%$ episodes in a study of patients with implantable cardioverter defibrillators [84]. The incidence of syncope or pre-syncope is $25 \%$ when VF is $<10$ seconds, compared with $62 \%$ if VF is $\geq 10$ seconds [84]. Therefore, CAS should be considered in the differential diagnosis of syncope.

On the other hand, severe CAS may cause fatal pulseless electrical activity or asystole without complications of ventricular tachycardia or VF [85-88]. Triple-vessel severe CAS can cause the heart to suddenly stop beating due to pulseless electrical activity and flash-freeze the entire myocardium in an instant, resulting in unrecognized coronary flow [88]. Consequently, contrast medium may stay in the coronary arteries for a prolonged period of time despite intracoronary administration of nitroglycerine. Prolonged continuous cardiac massage has been effective for resolving CAS-related pulseless electrical activity [88]. However, cardiac pacing or implantable cardioverter defibrillator might not restore frozen myocardium to viable muscle during pulseless electrical activity arrest, and may lead to unexplained death after the implantation [85, 88]. Furthermore, CAS-related ischemia of the sinus node artery or atrioventricular node artery can influence the occurrence of pulseless electrical activity or asystole [88]. Collectively, CAS may cause pulseless electrical activity or asystole without ventricular arrhythmias.

\section{Diagnosis}

\section{Differential Diagnosis}

For patients presenting with transient typical chest pain [89] with exertion or at rest, regardless of electrocardiographic ischemic changes, the diagnostic approach should include obstructive coronary artery disease (Figure 1). Other diagnosis that should be considered include gastroesophageal reflux disease with esophageal spasm [90] and microvascular angina, which has largely replaced cardiac syndrome $X[91]$.

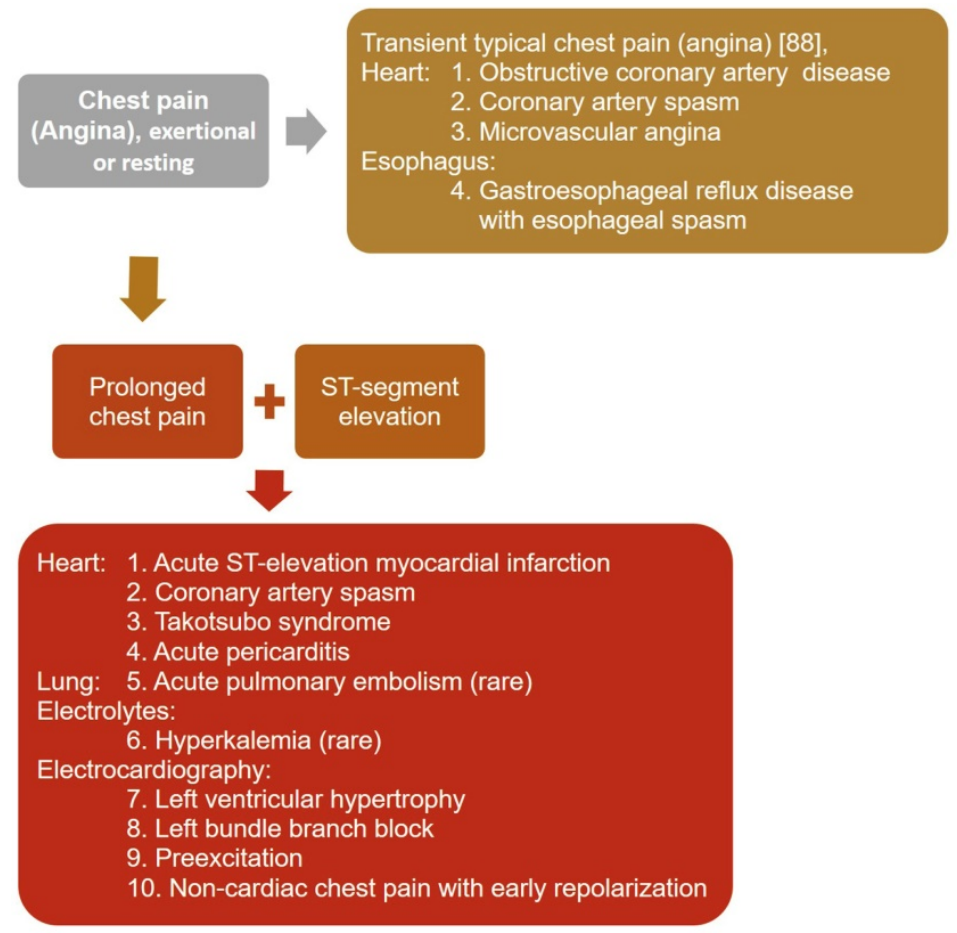

Figure 1. Diagnostic approach to patients presenting with transient typical chest pain, regardless of electrocardiographic ischemic changes, and prolonged chest pain with ST-segment elevation. 
When ST-segment elevation appears, the diagnoses most often confused with CAS, which presents with transient non-progressive ST-segment elevation, include acute ST-elevation myocardial infarction, acute pericarditis, left ventricular hypertrophy, left bundle branch block, preexcitation, non-cardiac chest pain associated with early repolarization [92], takotsubo syndrome [93], acute pulmonary embolism [94], and hyperkalemia [95] (Figure 1). Patients with acute ST-elevation myocardial infarction usually present with pain and ST-elevation for $>15$ minutes, which are not resolved by acute therapy with nitroglycerin or calcium channel blockers [96]. Acute pericarditis [97] and takotsubo syndrome [93] are characterized by repetitive episodes of chest pain for hours or days over a period of weeks or months. The chest pain in acute pericarditis is generally worse when lying supine and relieved by sitting, and might radiate to the neck, arms, or left shoulder, making differentiation from myocardial ischemia difficult [97].

\section{Diagnostic Coronary Angiography}

Although the key to the clinical diagnosis in medicine is the taking of a history, CAS may present with or without symptoms [38], occasionally relieved by exertion [10]. Furthermore, CAS can exhibit either normal electrocardiographic findings at the beginning of an attack or when the attack is mild [47], or ST-segment elevation or depression during the attack [64], hence a diagnosis of CAS cannot be directly made by symptoms [30]. Standard 12-lead electrocardiography [64], ambulatory electrocardiography [47], or exercise stress tests [10,98]. During the monitoring period of ambulatory electrocardiography, the attack may not appear [47]; however, brief episodes of ST-segment changes, heart blocks or potentially fatal ventricular arrhythmias may be detected (Table 2), which may allow for characterization of the attacks. Hence, ambulatory (holter) electrocardiography monitoring should be performed for patients in whom the diagnosis of CAS is being considered. Although a patient may have CAS if ST-segment elevation or depression of $\geq 0.1 \mathrm{mV}$ in at least 2 contiguous leads, pseudonormalization of $\mathrm{T}$ waves [23], or new negative $\mathrm{U}$ waves during exercise stress tests [17], the exercise testing results are usually negative in CAS [98]. Collectively, it is reasonable to refer a patient with suspected CAS for coronary angiography even if the stress test and ambulatory monitors are normal, particularly if episodes of pain do not occur during ambulatory monitoring.
A recently developed clinical diagnostic score for prediction of CAS in patients with acute chest pain consists of 6 factors, including allergies, asthma, angina attack at rest, ST-segment elevation, myocardial bridge, and hyperventilation test [99]. However, myocardial bridge is present anatomically in approximately $25 \%$ of patients based on autopsy and computed tomography, but only results in angiographically detectable systolic compression in less than $10 \%$ of patients [100]. Therefore, a larger scale of clinical data is needed to examine its predictive accuracy and specificity.

Coronary angiography with provocative testing, initially described in 1972 [101], is the only certain method of diagnosing CAS [102]. Although an occasional angiographic documentation of CAS in a patient with angina and normal electrocardiography at rest was reported by Gensini et al. in 1962 [103], it was not until the early 1970s that the hypothesis of CAS was provided by serial reports. While the $1^{\text {st }}$ CAS, probably catheter- or contrast- related, with reproduced chest pain was demonstrated angiographically in a patient with Prinzmetal angina in 1972 [83], spontaneously occurring CAS was not proved until 1973 when Prinzmetal angina of a non-smoking woman was demonstrated by coronary angiography [13]. The $1^{\text {st }}$ provocative testing using intravenous and intracoronary ergonovine were performed by the Cleveland Clinic in 1972 [101] and Hackett et al. in 1987 [104], respectively. Interestingly, Yasue et al. reported that the use of subcutaneous injection of methacholine induced CAS in 1974 [105], and the usefulness of intracoronary acetylcholine in 1988 [106].

In patients with ST-segment elevation during episodes of angina and a normal coronary angiography, provocative tests usually are not necessary for diagnosis of CAS [102]. Provoked CAS is defined as a reduction of $>50 \%$ [102], $>70 \%$ [106], $>75 \%$ [54, 101, 107, 108], >90\% [17, 55, 108, 109], or $99-100 \%$ [53] in luminal diameter with or without symptoms and/or ischemic ST-segment changes compared with postintracoronary nitroglycerin.

The diagnostic criteria of positive provocative testing for CAS was initially described by Chahine et al. according to [12, 30]: (1) appearance of $100 \%$ occlusion of a segment of coronary artery; (2) appearance of significant narrowing $(\geq 75 \%)$ of a segment of coronary artery; (3) the disappearance, either spontaneous or by administration of nitroglycerin, of the $\geq 75 \%$ narrowing or total occlusion. In humans with one-vessel obstructive coronary artery disease, basal resting myocardial blood flow remains constant regardless of the severity of coronary artery obstruction [110]. During 
hyperemia as in exertion, the ability to increase myocardial blood flow becomes impaired with obstruction $>50 \%$ and is virtually abolished at $>70 \%$ [111]. In patients with one-vessel obstructive coronary artery disease, a percent diameter stenosis of $\geq 50 \%$ and a percent area stenosis of $\geq 75 \%$ correspond to haemodynamically significant stenosis as evaluated by perfusion images [111]. Animal experiments indicate that only in the presence of a $\geq 90 \%$ acute lumen reduction does flow through the stenosis decrease below resting level [112]. CAS has been observed in obstructive coronary artery stenosis varying from $50 \%$ to subocclusive [22]; it is possible that a small reduction in luminal diasmeter, not easily detectable angiographically, may suffice to reduce the flow in these cases [22]. Therefore, Yasue et al. [47] suggested no limits on the reduction in luminal diameter for CAS diagnosis since myocardial ischemia results from the changes of vessel size. Individual patients have their own specific clinical features; hence, decisions regarding diagnosis of CAS should be based on the specific conditions of patients [17]. Collectively, because CAS can occur with variable threshold exertional angina and rarely with exertional angina only, a reduction of $>50 \%$ to $100 \%$ in luminal diameter with or without symptoms and/or ischemic ST-segment changes compared with postintracoronary nitroglycerin should be considered a positive test for CAS.

The severity and location of CAS and the associated electrocardiographic abnormalities have been variable in different episodes of CAS [13, 22, 63]. However, among the spasm-provoked arteries, the right coronary artery and left circumflex artery are the most and least frequently involved, respectively [12]. The susceptibility of the right coronary artery to spasm is demonstrated by the common occurrence of proximal spasm induced by the catheter tip during angiography [43].

During provocative tests, the occurrence of severe chest pain with ST-segment depression but without epicardial CAS has been termed microvascular CAS [108]. While a substantial proportion of CAS patients with angina involving the epicardial coronary arteries also have microvascular CAS [113], coronary microvascular dysfunction is a common finding in invasively managed angina patients with non-obstructive [114] or obstructive epicardial coronary artery disease [115]. The current gold standard for clinically invasive assessment of microvascular function in response to metabolic demands has been coronary flow reserve, which remains normal until diameter stenosis of epicardial large artery is $>50 \%[116,117]$. In addition, microvascular CAS can be inferred when coronary slow phenomenon, defined as TIMI frame count $>25$, appears [114]. Hence, in patients with non-obstructive or obstructive epicardial coronary artery disease, microvascular CAS may be considered one of the contributing factors for ischemia-like symptoms and myocardial ischemia. The involvement of the microvascular CAS adds a new diagnostic and therapeutic dimension to the problem, which needs to be considered in future studies, as coronary microvessels do not necessarily respond to currently used vasodilator agents in an identical fashion as epicardial coronary arteries.

The provocative testing at present involves the use of ergonovine or acetylcholine [102]. Ergonovine, an ergot alkaloid used to control postpartum uterine bleeding, was found in 1949 to provoke angina, and was proposed in 1963 as a diagnostic test for coronary disease [118]. Although methylergonovine, structurally similar to norepinephrine, and acetylcholine stimulate endothelial nitric oxide generation [119], they cause smooth muscle cell contraction in the setting of endothelial dysfunction [120-123]. In normal coronary arteries, only mild generalized vasoconstriction $\quad(<20 \%$ diameter reduction) would be induced [115, 124]. Ergonovine testing in the catheterization laboratory was used in the late1970s and early 1980s to help identify the mechanism of chest pain when non-obstructive coronary artery disease was found by angiography. In early studies, however, patients receiving very high doses of intravenous ergonovine frequently had severe angina and a reported death in a small series caused the intravenous route to be abandoned [125]. The frequency of provoked CAS by the intracoronary administration is about 2.5 -fold higher than that by the intravenous administration of ergonovine and acetylcholine [28, 30]; however, there is no difference concerning the incidence of provoked CAS between ergonovine and acetylcholine [126]. While provoked CAS by ergonovine tends to be proximal and focal, CAS provoked by acetylcholine is distal and diffuse [127-129]. Although the intracoronary injection of ergonovine and acetylcholine provoked CAS in 65\% and $80 \%$ in a previous study [128], respectively, no differences existed regarding the provoked CAS between intracoronary ergonovine and acetylcholine in a later study [129]. Further studies are needed to evaluate the coronary response between the ergonovine and acetylcholine examinations.

To ensure a valid diagnosis, vasodilators (calcium antagonists and nitrates) must be withdrawn for $\geq 24$ hours except for sublingual nitroglycerin if necessary [17, 102, 130]. Prophylactic administration of coronary vasodilators at the beginning of coronary angiography should be avoided [12]. On the other 
hand, the nitroglycerin or atropine [131] solution for intracoronary administration must be well prepared before starting provocative testing to abolish documented CAS immediately. The intracoronary administration of methylergonovine affords the opportunity to evaluate the left and right coronary arteries separately with small dosing increments of 5 to $10 \mu \mathrm{g}$ and a total dose not to exceed $50 \mu \mathrm{g}$ [102]. The effectiveness of intracoronary administration of acetylcholine in doses of 10 to $100 \mu \mathrm{g}$ is comparable to methylergonovine [102, 132, 133]. Cautious administration of increasing doses of intracoronary ergonovine was given, with angiography several minutes after each dose or until whenever chest pain or electrocardiographic changes occurred. During coronary angiography, 2 sets of coronary cineangiograms are performed before and after the administration of nitroglycerin [12].

About one-third of patients with dilated cardiomyopathy has CAS and multiple episodes and locations of CAS may lead to HFrEF [50]. To help determine the causes of HFrEF for patients with no fixed coronary artery obstruction, the spasm provocative testing should be performed with careful attention [126, 134] as it has a potential to cause angina, hypotension and various arrhythmias. For intracoronary acetylcholine provocative testing, 100 $\mu \mathrm{g}$ acetylcholine is injected directly into the left and right coronary arteries separately [53]. To provoke CAS by ergonovine (methylergometrine maleate), ergonovine was injected in incremental doses of 1,5 , 10 , and $30 \mu \mathrm{g}$ into the left and 1, 5, and $10 \mu \mathrm{g}$ into the right coronary artery over 1 minute with a 3-minute interval between each injection [54]. In previous Japanese studies [50,55], acetylcholine was injected in incremental doses of 20,50, and $100 \mu \mathrm{g}$ in $5-10 \mathrm{ml} 0.9 \%$ saline solution into the left and of 20, 50 [50,56], and 80 [55] $\mu \mathrm{g}$ into the right coronary arteries over 20 seconds, On the other hand, ergonovinie in $0.9 \%$ saline solution was injected in total doses of 40 $\mu \mathrm{g} / 40 \mathrm{ml}$ into the RCA and of $64 \mu \mathrm{g} / 64 \mathrm{ml}$ into the LCA over 4 min each [50]. Although severe HFrEF was previously considered an absolute contraindication [102], CAS provocative testing has been safely performed recently [50, 53-55].

While the complications of intracoronary provocative testing include angina, hypotension, dyspnea, flushing, nausea, vomiting and various arrhythmias [47, 135], systemic effects, such as hypertension, are avoided [136]. No procedurerelated mortality, myocardial infarction or irreversible complications have been reported during intracoronary provocative testing $[28,123]$. Because $\mathrm{VF}$ is a possible complication following intracoronary provocative testing, its use inside the cardiac catheterization laboratory is highly recommended. The absolute contraindications to methylergonovine include high-grade left main coronary artery disease, severe left ventricular dysfunction, moderate to severe aortic stenosis, severe hypertension and pregnancy [102]. A multicenter, retrospective study showed that the rates of serious cardiac complications were $<1 \%$ in patients undergoing a pharmacological provocative testing [137]. However, acetylcholine provocative testing were associated with a higher rate of serious cardiac complications than ergonovine tests (odds ratio: 1.75, 95\% confidence interval: 1.13-2.69, $\mathrm{P}$ $=0.011$ ) [137].

\section{Conclusion}

The management of angina should not be oversimplified as CAS not only induces angina but also causes HFrEF. Patients with HFrEF and CAS may have associated atrial fibrillation. In addition, asymptomatic CAS patients could die suddenly of VF, pulseless electrical activity or asystole. Awareness of CAS is important for clinicians for appropriate management, and preventing progression to more severe atrioventricular block necessitating permanent pacemaker implant. Furthermore, since the coronary vasoconstriction is nonspecific and the angina of CAS is not relieved by rest, CAS-related angina in the same patient may occur under different conditions. As a result, it is important to identify patients with CAS because treatment strategies are different between obstructive coronary artery disease and CAS, and the administration of calcium channel blockers is necessary to improve left ventricular function for CAS-relarted HFrEF.

\section{Abbreviations}

CAS: coronary artery spasm; HFrEF: heart failure with reduced ejection fraction; VF: ventricular fibrillation.

\section{Acknowledgements}

This work was supported by National Science Council of Taiwan grant to Ming-Yow Hung (MOST-108-2314-B-038-119-MY3). This study was also supported by grants from Taipei Medical University (107TMU-SHH-02) to Ming-Yow Hung. Neither of these institutions had any involvement in the conduct of the research, preparation of the article, or the decision to publish the study results.

\section{Competing Interests}

The authors have declared that no competing interest exists. 


\section{References}

1. Friedberg CK. Some comments and reflections on changing interests and new developments in angina pectoris. Circulation. 1972; 46: 1037-47.

2. Gibbons RJ, Abrams J, Chatterjee K, Daley J, Deedwania PC, Douglas JS, et al.; American College of Cardiology; American Heart Association Task Force on Practice Guidelines. Committee on the Management of Patients With Chronic Stable Angina. ACC/AHA 2002 guideline update for the management of patients with chronic stable angina--summary article: a report of the American College of Cardiology/American Heart Association Task Force on Practice Guidelines (Committee on the Management of Patients With Chronic Stable Angina). Circulation. 2003; 107: 149-58.

3. Apstein CS, Grossman W. Opposite initial effects of supply and demand ischemia on left ventricular diastolic compliance: the ischemia-diastolic paradox. J Mol Cell Cardiol. 1987; 19: 119-28.

4. Wilson RF, Marcus ML, White CW. Prediction of the physiologic significance of coronary arterial lesions by quantitative lesion geometry in patients with limited coronary artery disease. Circulation. 1987; 75: 723-32.

5. Maseri A, Parodi O, Severi S, Pesola A. Transient transmural reduction of myocardial blood flow demonstrated by thallium-201 scintigraphy, as a cause of variant angina. Circulation. 1976; 54: 280-8.

6. Harrison TR, Reeves TJ. Some etiologic and epidemiologic considerations. T.R. Harrison, T.J. Reeves (Eds.), Principles and problems of ischemic heart disease, Year Book Publishers, Chicago, 1968, $33-53$.

7. Blumgart HL, Schlesinger MJ, Davis D. Studies on the relation of the clinical manifestations of angina pectoris, coronary thrombosis and myocardial infarction to the pathologic findings. Am Heart J. 1940; 19: 1-91.

8. Blumgart HL, Schlesinger MJ, Zoll PM. Angina pectoris, coronary failure and acute myocardial infarction. The role of coronary occlusions and collateral circulation. JAMA. 1941; 116: 91-7.

9. Zoll PM, Wessler S, Blumgart HL: Angina pectoris: a clinical and pathologic correlation. Am J Med. 1951; 11: 331-57.

10. Prinzmetal M, Kennamer R, Merliss R, Wada T, Bor N. Angina pectoris. I. A variant form of angina pectoris; preliminary report. Am J Med. 1959; 27: 375-88.

11. MacAlpin RN, Kattus AA, Alvaro AB. Angina pectoris at rest with preservation of exercise capacity: Prinzmetal's variant angina. Circulation. 1973; 47: 946-58.

12. Chahine RA, Raizner AE, Ishimori T, Luchi RJ, McIntosh HD. The incidence and clinical implications of coronary artery spasm. Circulation. 1975; 52: 972-8.

13. Oliva PB, Potts DE, Pluss RG. Coronary arterial spasm in Prinzmetal angina. Documentation by coronary arteriography. N Engl J Med. 1973; 288 :745-51.

14. Sones FM Jr, Shirey EK. Cine coronary arteriography. Mod Concepts Cardiovasc Dis. 1962; 31: 735-8

15. Cheng TO, Bashour T, Kelser GA, Jr., Weiss L, Bacos J. Variant angina of prinzmetal with normal coronary arteriograms. A variant of the variant. Circulation. 1973; 47: 476-85.

16. Maseri A, Mimmo R, Chierchia S, Marchesi C, Pesola A, L'Abbate A. Coronary artery spasm as a cause of acute myocardial ischemia in man. Chest. 1975; 68: 625-33.

17. JCS Joint Working Group. Guidelines for diagnosis and treatment of patients with vasospastic angina (Coronary Spastic Angina) (JCS 2013). Circ J. 2014; 78: 2779-801.

18. Cheng CW, Yang NI, Lin KJ, Hung MJ, Cherng WJ. Role of coronary spasm for a positive noninvasive stress test result in angina pectoris patients without hemodynamically significant coronary artery disease. Am J Med Sci. 2008; 335: 354-62.

19. Hung MJ, Hu P, Hung MY. Coronary artery spasm: review and update. Int J Med Sci. 2014; 11: 1161-71.

20. Kounis NG, Zavras GM. Histamine-induced coronary artery spasm: the concept of allergic angina. Br J Clin Pract. 1991; 45: 121-8

21. Kounis NG, Koniari I, Velissaris D, Tzanis G, Hahalis G. Kounis Syndrome-not a Single-organArterial Disorder but a Multisystem and Multidisciplinary Disease. Balkan Med J. 2019; 36: 212-21.

22. Maseri A. Pathogenetic mechanisms of angina pectoris: expanding views. $\mathrm{Br}$ Heart J. 1980; 43: 648-60.

23. Maseri A, Severi S, Nes MD, L'Abbate A, Chierchia S, Marzilli M, et al. "Variant" angina: one aspect of a continuous spectrum of vasospastic myocardial ischemia. Pathogenetic mechanisms, estimated incidence and clinical and coronary arteriographic findings in 138 patients. Am J Cardiol. 1978; 42: 1019-35.

24. Hung MY, Mao CT, Hung MJ, Wang JK, Lee HC, Yeh CT, et al. Coronary Artery Spasm as Related to Anxiety and Depression: A Nationwide Population-Based Study. Psychosom Med. 2019; 81: 237-45.

25. Schang SJ Jr, Pepine CJ. Transient asymptomatic S-T segment depression during daily activity. Am J Cardiol. 1977; 39: 396-402.

26. Mudge GH Jr, Grossman W, Mills RM Jr, Lesch M, Braunwald E. Reflex increase in coronary vascular resistance in patients with ischemic heart disease. N Engl J Med. 1976; 295: 1333-7.

27. Beltrame JF, Sasayama S, Maseri A. Racial heterogeneity in coronary artery vasomotor reactivity: differences between Japanese and Caucasian patients. J Am Coll Cardiol. 1999; 33: 1442-52.

28. Sueda S, Kohno H, Fukuda H, Ochi N, Kawada H, Hayashi Y, et al. Frequency of provoked coronary spasms in patients undergoing coronary arteriography using a spasm provocation test via intracoronary administration of ergonovine. Angiology. 2004; 55: 403-11.

29. Hung MY, Hsu KH, Hung MJ, Cheng CW, Cherng WJ. Interactions among gender, age, hypertension and C-reactive protein in coronary vasospasm. Eur J Clin Invest. 2010; 40: 1094-103.

30. Bertrand ME, LaBlanche JM, Tilmant PY, Thieuleux FA, Delforge MR, Carre AG, et al. Frequency of provoked coronary arterial spasm in 1089 consecutive patients undergoing coronary arteriography. Circulation. 1982; 65: 1299-306.

31. Hung MJ, Cherng WJ, Cheng CW, Li LF. Comparison of serum levels of inflammatory markers in patients with coronary vasospasm without significant fixed coronary artery disease versus patients with stable angina pectoris and acute coronary syndromes with significant fixed coronary artery disease. Am J Cardiol. 2006; 97: 1429-34.

32. Hung MJ, Cheng CW, Yang NI, Hung MY, Cherng WJ. Coronary vasospasm-induced acute coronary syndrome complicated by life-threatening cardiac arrhythmias in patients without hemodynamically significant coronary artery disease. Int I Cardiol. 2007; 117: 37-44.

33. Ong $\mathrm{P}$, Athanasiadis A, Hill S, Vogelsberg H, Voehringer M, Sechtem U. Coronary artery spasm as a frequent cause of acute coronary syndrome: The CASPAR (Coronary Artery Spasm in Patients With Acute Coronary Syndrome) Study. J Am Coll Cardiol. 2008; 52: 523-7.

34. Goto A, Ito S, Kondo H, Nomura Y, Yasue N, Suzumura H, et al. Evaluation of adjunctive intracoronary administration of acetylcholine following intravenous infusion of ergonovine to provoke coronary artery spasm. J Cardiol. 1999; 34: 309-16.

35. Da CA, Isaaz K, Faure E, Mourot S, Cerisier A, Lamaud M. Clinical characteristics, aetiological factors and long-term prognosis of myocardial infarction with an absolutely normal coronary angiogram; a 3-year follow-up study of 91 patients. Eur Heart J. 2001; 22: 1459-65.

36. Yasue H, Mizuno Y, Harada E. Coronary artery spasm - Clinical features, pathogenesis and treatment. Proc Jpn Acad Ser B Phys Biol Sci. 2019; 95: 53-66.

37. Maseri A, L'Abbate A, Baroldi G, Chierchia S, Marzilli M, Ballestra AM, et al. Coronary vasospasm as a possible cause of myocardial infarction. A conclusion derived from the study of "preinfarction" angina. N Engl J Med. 1978; 299: 1271-7.

38. Yasue H, Kugiyama K. Coronary spasm: clinical features and pathogenesis. Intern Med. 1997; 36: 760-5.

39. Hung MJ, Hung MY, Cheng CW, Yang NI, Cherng WJ. Clinical characteristics of patients with exercise-induced ST-segment elevation without prior myocardial infarction. Circ J. 2006; 70: 254-61.

40. Nakamura M, Takeshita A, Nose Y. Clinical characteristics associated with myocardial infarction, arrhythmias, and sudden death in patients with vasospastic angina. Circulation. 1987; 75: 1110-6.

41. Hamilton KK, Pepine CJ. A renaissance of provocative testing for coronary spasm? J Am Coll Cardiol. 2000; 35: 1857-59.

42. Lange RL, Reid MS, Tresch DD, Keelan MH, Bernhard VM, Coolidge G. Nonatheromatous ischemic heart disease following withdrawal from chronic industrial nitroglycerin exposure. Circulation. 1972; 46: 666-78.

43. Higgins CB, Wexler L, Silverman JF, Schroeder JS. Clinical and arteriographic features of Prinzmetal's variant angina: documentation of etiologic factors. Am J Cardiol. 1976; 37: 831-9.

44. Hillis LD, Braunwald E. Coronary-artery spasm. N Engl J Med. 1978; 299: 695-702.

45. Araki H, Koiwaya Y, Nakagaki O, Nakamura M. Diurnal distribution of ST-segment elevation and related arrhythmias in patients with variant angina: a study by ambulatory ECG monitoring. Circulation. 1983; 67: 995-1000.

46. Yasue H, Omote S, Takizawa A, Nagao M. Coronary arterial spasm in ischemic heart disease and its pathogenesis. A review. Circ Res. 1983; 52: I147-52.

47. Yasue $\mathrm{H}$, Nakagawa H, Itoh T, Harada E, Mizuno Y. Coronary artery spasmclinical features, diagnosis, pathogenesis, and treatment. J Cardiol. 2008; 51: 2-17.

48. Jougasaki M, Yasue H, Takahashi K. Perivascular nerve lesion of the coronary artery involved in spasm in a patient with variant angina. Pathology. 1989; 21: 304-7.

49. Otsuka K, Yanaga T, Watanabe H. Variant angina and REM sleep. Am Heart J. 1988; 115: 1343-6.

50. Sueda S, Kohno H, Oshita A, Izoe Y, Nomoto T, Fukuda H. Vasospastic heart failure: multiple spasm may cause transient heart failure? J Cardiol. 2009; 54: $452-9$.

51. Factor SM, Minase T, Cho S, Dominitz R, Sonnenblick EH. Microvascular spasm in the cardiomyopathic Syrian hamster: a preventable cause of focal myocardial necrosis. Circulation. 1982; 66: 342-54.

52. Gaasch WH, Adyanthaya AV, Wang VH, Pickering E, Quinones MA, Alexander JK. Prinzmetal's variant angina: hemodynamic and angiographic observations during pain. Am J Cardiol. 1975; 35: 683-90.

53. Sakata K, Nawada R, Ohbayashi K, Tamekiyo H, Yoshida H. Diffuse and severe left ventricular dysfunction induced by epicardial coronary artery spasm. Angiology. 2000; 51: 837-47.

54. Nishi I, Ilda K, Kawano S, Masumi T, Fumikura Y, Ohtsuka S, et al. Effects of anti-vasospastic agents in Japanese patients with dilated cardiomyopathy and coronary vasospasm. Jpn Heart J. 2002; 43: 333-42.

55. Inami $T$, Kataoka $M$, Shimura $N$, Ishiguro $H$, Kohshoh $H$, Taguchi $H$, et al. Left ventricular dysfunction due to diffuse multiple vessel coronary artery spasm can be concealed in dilated cardiomyopathy. Eur J Heart Fail. 2012; 14: 1130-8. 
56. Oda S, Fujii $Y$, Takemoto $H$, Nomura $S$, Nakayama H, Toyota $Y$, et al. Heart failure in which coronary spasms played an important role. Intern Med. 2014; 53: 227-32.

57. Guazzi M, Polese A, Fiorentini C, Magrini F, Bartorelli C. Left ventricular performance and related haemodynamic changes in Prinzmetal's variant angina pectoris. Br Heart J. 1971; 33: 84-94.

58. Figulla HR, Vetterlein F, Glaubitz M, Kreuzer H. Inhomogenous capillary flow and its prevention by verapamil and hydralazine in the cardiomyopathic Syrian hamster. Circulation. 1987; 76: 208-16

59. Figulla HR, Rechenberg JV, Wiegand V, Soballa R, Kreuzer H. Beneficial effects of long-term diltiazem treatment in dilated cardiomyopathy. J Am Coll Cardiol. 1989; 13: 653-8.

60. Multicenter Diltiazem Postinfarction Trial Research Group. The effect of diltiazem on mortality and reinfarction after myocardial infarction. $\mathrm{N}$ Engl J Med. 1988; 319: 385-92.

61. WRITING COMMITTEE MEMBERS, Yancy CW, Jessup M, Bozkurt B, Butler J, Casey DE Jr, Drazner MH, et al.; American College of Cardiology Foundation/American Heart Association Task Force on Practice Guidelines. 2013 ACCF/AHA guideline for the management of heart failure: a report of the American College of Cardiology Foundation/American Heart Association Task Force on practice guidelines. Circulation. 2013; 128: e240-327.

62. Hă̌at R, Halphen C, Derrida JP, Chiche P. Pseudonormalization of the repolarization during transient episodes of myocardial ischemia. Am Heart J. 1977: 94: 390-1.

63. Prinzmetal M, Ekmekci A, Toyoshima H, Kwoczynski JK. Angina pectoris. III. Demonstration of a chemical origin of ST deviation in classic angina pectoris, its variant form, early myocardial infarction, and some noncardiac conditions. Am J Cardiol. 1959; 3: 276-93.

64. Yasue H, Omote S, Takizawa A, Masao N, Hyon H, Nishida S, et al. Comparison of coronary arteriographic findings during angina pectoris associated with S-T elevation or depression. Am J Cardiol. 1981; 47: 539-46.

65. Prinzmetal M, Goldman A, Shubin H, Bor N, Wada T. Angina pectoris. II. Observations on the classic form of angina pectoris; preliminary report. Am Heart J. 1959; 57: 530-43.

66. Ozaki Y, Keane D, Serruys PW. Fluctuation of spastic location in patients with vasospastic angina: a quantitative angiographic study. J Am Coll Cardiol. 1995; 26: 1606-14.

67. Waters DD, Szlachcic J, Theroux P, Dauwe F, Mizgala HF. Ergonovine testing to detect spontaneous remissions of variant angina during long-term treatment with calcium antagonist drugs. Am J Cardiol. 1981; 47: 179-84.

68. Whittle JL, Feldman RL, Pepine CJ, Curry RC, Conti CR. Variability of electrocardiographic responses to repeated ergonovine provocation in variant angina patients with coronary artery spasm. Am Heart J. 1982; 103: 161-7.

69. Bashour T. Cardiac rhythm disorders complicating coronary arterial spasm. Clin Cardiol. 1984; 7: 510-2.

70. Akhtar MM, Akhtar R, Akhtar A, Akhtar J. An unusual cause of blackout with transient loss of consciousness: Prinzmetal angina. BMJ Case Rep. 2012; 2012.

71. Seniuk W, Mularek-Kubzdela T, Grygier M, Grajek S, Cieśliński A. Cardiac arrest related to coronary spasm in patients with variant angina: a three-case study. J Intern Med. 2002; 252: 368-76.

72. Hung MJ, Wang CH, Kuo LT, Cherng WJ. Coronary artery spasm-induced paroxysmal atrial fibrillation-a case report. Angiology. 2001; 52: 559-62.

73. Myerburg RJ, Kessler KM, Mallon SM, Cox MM, deMarchena E, Interian A Jr, Castellanos A. Life-threatening ventricular arrhythmias in patients with silent myocardial ischemia due to coronary-artery spasm. N Engl J Med. 1992; 326: 1451-55.

74. Selzer A, Langston M, Ruggeroli C, Cohn K. Clinical syndrome of variant angina with normal coronary arteriogram. N Engl J Med. 1976; 295: 1343-7.

75. Kerin NZ, Rubenfire M, Naini M, Wajszczuk WJ, Pamatmat A, Cascade PN. Arrhythmias in variant angina pectoris. Relationship of arrhythmias to ST-segment elevation and R-wave changes. Circulation. 1979; 60: 1343-50.

76. Itoh E, Suzuki K, Tanabe Y. A case of vasospastic angina presenting Brugada-type ECG abnormalities. Jpn Circ J. 1999; 63: 493-5.

77. Alhaji M. Intermittent left bundle branch block caused by coronary vasospasm. Avicenna J Med. 2013; 3: 50-2.

78. Maseri A, Severi S, Marzullo P. Role of coronary arterial spasm in sudden coronary ischemic death. Ann N Y Acad Sci. 1982; 382: 204-17.

79. Romagnoli E, Lanza GA. Acute myocardial infarction with normal coronary arteries: role of coronary artery spasm and arrhythmic complications. Int J Cardiol. 2007; 117: 3-5.

80. Dalen JE, Ockene IS, Alpert JS. Coronary spasm, coronary thrombosis, and myocardial infarction: a hypothesis concerning the pathophysiology of acute myocardial infarction. Am Heart J. 1982; 104: 1119-24.

81. Olgin JE, Zipes DP. Specific arrhythmias: diagnosis and treatment. In: Zipes DP, Libby P, Bonow RO, Braunwald E, Eds. Heart Disease: A Textbook of Cardiovascular Medicine. 7th ed. Philadelphia: Saunders, 2005; 853.

82. Hung MY, Hung MJ, Cheng CW, Yang NI, Cherng WJ. Safety and predictors of a positive result of intracoronary ergonovine testing in patients with ischemic heart disease without hemodynamically significant coronary artery stenosis in Taiwan. Acta Cardiol Sin. 2007; 23: 150-9.

83. Dhurandhar RW, Watt DL, Silver MD, Trimble AS, Adelman AG. Prinzmetal's variant form of angina with arteriographic evidence of coronary arterial spasm. Am J Cardiol. 1972; 30: 902-5.
84. Farmer DM, Swygman CA, Wang PJ, Mark Estes NA 3rd, Link MS. Evidence that nonsustained polymorphic ventricular tachycardia causes syncope (data from implantable cardioverter defibrillators). Am J Cardiol. 2003; 91: 606-9.

85. Letsas KP, Filippatos GS, Efremidis M, Sideris A, Kardaras F. Secondary prevention of sudden cardiac death in coronary artery spasm: is implantable cardioverter defibrillator always efficient? Int J Cardiol. 2007; 117: 141-3.

86. Martin J, Sanfilippo F, Bradlow W, Sabharwal NK. Severe vasospastic angina complicated by multiple pulseless electrical activity arrests. Lancet. 2013; 382: 478 .

87. Lother A, Beyersdorf F, Osterhues HH, Bode C, Wengenmayer T. Recurrent pulseless electrical activity in a patient with coronary vasospasm and supravalvular aortic stenosis: a case report. BMC Cardiovasc Disord. 2016; 16: 100.

88. Sueda S, Fujimoto K, Sasaki Y, Habara H, Kohno H. Cardiogenic Shock due to Pulseless Electrical Activity Arrest Associated with Severe Coronary Artery Spasm. Intern Med. 2018; 57: 2853-7.

89. Diamond GA. A clinically relevant classification of chest discomfort. J Am Coll Cardiol. 1983; 1: 574-5.

90. Dent J1, El-Serag HB, Wallander MA, Johansson S. Epidemiology of gastro-oesophageal reflux disease: a systematic review. Gut. 2005; 54: 710-7.

91. Jones E, Eteiba W, Merz NB. Cardiac syndrome $X$ and microvascular coronary dysfunction. Trends Cardiovasc Med. 2012; 22: 161-8.

92. Hanna EB, Glancy DL. ST-segment elevation: Differential diagnosis, caveats. Cleve Clin J Med. 2015; 82: 373-84

93. Barker S, Solomon H, Bergin JD, Huff JS, Brady WJ. Electrocardiographic ST-segment elevation: Takotsubo cardiomyopathy versus ST-segment elevation myocardial infarction--a case series. Am J Emerg Med. 2009; 27: 220-6

94. Cheng TO. Mechanism of ST-elevation in acute pulmonary embolism. Int J Cardiol. 2005; 103: 221-3.

95. Heckle M, Agarwal M, Alsafwah S. ST Elevations in the Setting of Hyperkalemia. JAMA Intern Med. 2018; 178: 133-4.

96. Wakai AP. Myocardial infarction (ST-elevation). BMJ Clin Evid. 2009; 2009. pii: 0202 .

97. Troughton RW, Asher CR, Klein AL. Pericarditis. Lancet. 2004; 363: 717-27.

98. Cheng TO. Ergonovine test for coronary artery spasm. Int J Cardiol. 2007; 114: 249-50.

99. Yaowang Lin, Haiyan Qin, Ruimian Chen, Qiyun Liu, Huadong Liu, Shaohong Dong. A comprehensive clinical diagnostic score system for prediction of coronary artery spasm in patients with acute chest pain. Int J Cardiol Heart Vasc. 2019; 22: 205-9.

100. Michael S. Lee, $\mathrm{CH}$ Chen. Myocardial Bridging: An Up-to-Date Review. J Invasive Cardiol. 2015; 27: 521-8.

101. Heupler, FA Jr. Provocative testing for coronary arterial spasm: risk, method and rationale. Am J Cardiol. 1980; 46: 335-7.

102. Scanlon PJ, Faxon DP, Audet AM, Carabello B, Dehmer GJ, Eagle KA, et al. ACC/AHA guidelines for coronary angiography. A report of the American College of Cardiology/American Heart Association Task Force on practice guidelines (Committee on Coronary Angiography). Developed in collaboration with the Society for Cardiac Angiography and Interventions. J Am Coll Cardiol. 1999; 33: 1756-824.

103. Gensini GG, Di Giorgi S, Murad-Netto S, Black A. Arteriographic demonstration of coronary artery spasm and its release after the use of a vasodilator in a case of angina pectoris and in the experimental animal. Angiology. 1962; 13: 550-3.

104. Hackett D, Larkin S, Chierchia S, Davies G, Kaski JC, Maseri A. Induction of coronary artery spasm by a direct local action of ergonovine. Circulation. 1987; 75: 577-82.

105. Yasue H, Touyama M, Shimamoto M, Kato H, Tanaka S, Akiyama F. Role of autonomic nervous system in the pathogenesis of Prinzmetal's variant form of angina. Circulation. 1974; 50: 534-9.

106. Baim DS. Coronary angiography. In: Baim DS, eds. Grossman's cardiac catheterization, angiography, and intervention. 7th ed. Philadelphia: Lippincott Williams \& Wilkins; 2006: 215.

107. Bertrand ME, Lablanche JM, Tilmant PY, Thieuleux FA, Delforge MG, Chahine RA. The provocation of coronary arterial spasm in patients with recent transmural myocardial infarction. Eur Heart J. 1983; 4: 532-5.

108. Task Force Members, Montalescot G, Sechtem U, Achenbach S, Andreotti F, Arden C, Budaj A, et al. 2013 ESC guidelines on the management of stable coronary artery disease: the Task Force on the management of stable coronary artery disease of the European Society of Cardiology. Eur Heart J. 2013; 34: 2949-3003.

109. Beltrame JF, Crea F, Kaski JC, Ogawa H, Ong P, Sechtem U, et al.; Coronary Vasomotion Disorders International Study Group (COVADIS). International standardization of diagnostic criteria for vasospastic angina. Eur Heart J. 2017; 38: 2565-8

110. Uren NG, Melin JA, De Bruyne B, Wijns W, Baudhuin T, Camici PG. Relation between myocardial blood flow and the severity of coronary-artery stenosis. N Engl J Med. 1994; 330: 1782-8.

111. Gottsauner-Wolf M, Sochor H, Moertl D, Gwechenberger M, Stockenhuber F, Probst P. Assessing coronary stenosis. Quantitative coronary angiography versus visual estimation from cine-film or pharmacological stress perfusion images. Eur Heart J. 1996; 17: 1167-74.

112. Gregg DE, Bedynek JL Jr. Compensatory changes in the heart during progressive coronary artery stenosis. In: Maseri A, Klassen GA, Lesch M, eds. 
Primary and secondary angina pectoris New York: Grune \& Stratton, 1978: 3-11.

113. Ong P, Athanasiadis A, Borgulya G, Mahrholdt H, Kaski JC, Sechtem U. High prevalence of a pathological response to acetylcholine testing in patients with stable angina pectoris and unobstructed coronary arteries. The ACOVA Study (Abnormal COronary VAsomotion in patients with stable angina and unobstructed coronary arteries). J Am Coll Cardiol. 2012; 59: 655-62.

114. Ong P, Camici PG, Beltrame JF, Crea F, Shimokawa H, Sechtem U, et al.; Coronary Vasomotion Disorders International Study Group (COVADIS). International standardization of diagnostic criteria for microvascular angina. Int J Cardiol. 2018; 250: 16-20.

115. Corcoran D, Young R, Adlam D, McConnachie A, Mangion K, Ripley D, et al. Coronary microvascular dysfunction in patients with stable coronary artery disease: The CE-MARC 2 coronary physiology sub-study. Int J Cardiol. 2018; 266: 7-14.

116. Gould KL, Lipscomb K, Hamilton GW. Physiologic basis for assessing critical coronary stenosis. Instantaneous flow response and regional distribution during coronary hyperemia as measures of coronary flow reserve. Am J Cardiol. 1974; 33: 87-94.

117. Duncker DJ, Koller A, Merkus D, Canty JM Jr. Regulation of coronary blood flow in health and ischemic heart disease. Prog Cardiovasc Dis. 2015; 57: 409-22.

118. Schroeder JS. Variant angina. In: Parmley WW, Chatterjee K, editors. Cardiology. Philadelphia: JB Lippincott, 1991: 1-16.

119. Henry PD, Yokoyama M. Supersensitivity of atherosclerotic rabbit aorta to ergonovine: mediation by a serotonergic mechanism. J Clin Invest. 1980; 66: 306-13.

120. Furchgott RF, Zawadzki JV. The obligatory role of endothelial cells in the relaxation of arterial smooth muscle by acetylcholine. Nature. 1980; 288: 373-6.

121. Martin W, Villani GM, Jothianandan D, Furchgott RF. Selective blockade of endothelium-dependent and glyceryl trinitrate-induced relaxation by hemoglobin and by methylene blue in the rabbit aorta. J Pharmacol Exp Ther. 1985; 232: 708-16.

122. Shimokawa H, Flavahan NA, Shepherd IT, Vanhoutte PM Endothelium-dependent inhibition of ergonovine-induced contraction is impaired in porcine coronary arteries with regenerated endothelium. Circulation. 1989; 80: 643-50.

123. Zaya M, Mehta PK, Bairey Merz CN. Provocative Testing for Coronary Reactivity and Spasm. J Am Coll Cardiol. 2014; 63: 103-9.

124. Lambert CR, Pepine CJ. Coronary artery spasm: American view. Coron Artery Dis. 1990; 1: $654-9$.

125. Buxton A, Goldberg S, Hirshfeld JW, Wilson J, Mann T, Williams DO, et al. Refractory ergonovine-induced coronary vasospasm: importance of intracoronary nitroglycerin. Am J Cardiol. 1980; 46: 329-34.

126. Sueda $\mathrm{S}$, Kohno $\mathrm{H}$, Fukuda $\mathrm{H}$, Ochi $\mathrm{N}$, Kawada $\mathrm{H}$, Hayashi $\mathrm{Y}$, et al. Clinical impact of selective spasm provocation tests: comparisons between acetylcholine and ergonovine in 1508 examinations. Coron Artery Dis. 2004; 15: 491-7.

127. Suzuki Y1, Tokunaga S, Ikeguchi S, Miki S, Iwase T, Tomita T, et al. Induction of coronary artery spasm by intracoronary acetylcholine: comparison with intracoronary ergonovine. Am Heart J. 1992; 124: 39-47.

128. Kanazawa K, Suematsu M, Ishida T, Hirata K, Kawashima S, Akita H, et al. Disparity between serotonin- and acetylcholine-provoked coronary artery spasm. Clin Cardiol. 1997; 20: 146-52.

129. Sueda $\mathrm{S}$, Kohno $\mathrm{H}$, Fukuda $\mathrm{H}$, Ochi $\mathrm{N}$, Kawada $\mathrm{H}$, Hayashi $\mathrm{Y}$, et al. Induction of coronary artery spasm by two pharmacological agents: comparison between intracoronary injection of acetylcholine and ergonovine. Coron Artery Dis. 2003; 14: 451-7.

130. Hung MJ, Hsu KH, Hu WS, Chang NC, Hung MY. C-reactive protein for predicting prognosis and its gender-specific associations with diabetes mellitus and hypertension in the development of coronary artery spasm. PloS One. 2013; 8: e77655.

131. Yasue H, Horio Y, Nakamura N, Fujii H, Imoto N, Sonoda R, et al. Induction of coronary artery spasm by acetylcholine in patients with variant angina: possible role of the parasympathetic nervous system in the pathogenesis of coronary artery spasm. Circulation. 1986; 74: 955-63.

132. Tada M, Kuzuya T, Inoue M, Kodama K, Mishima M, Yamada M, et al. Elevation of thromboxane B2 levels in patients with classic and variant angina Pectoris. Circulation. 1981; 64: 1107-15.

133. Okumura K, Yasue H, Horio Y, Takaoka K, Matsuyama K, Kugiyama K, et al. Multivessel coronary spasm in patients with variant angina: a study with intracoronary injection of acetylcholine. Circulation. 1988; 77: 535-42.

134. Sueda S, Saeki H, Otani T, Mineoi K, Kondou T, Yano K, et al. Major complications during spasm provocation tests with an intracoronary injection of acetylcholine. Am J Cardiol. 2000; 85: 391-4, A10.

135. Eshaghpour E, Mattioli L, Williams ML, Moghadam AN. Acetylcholine in the treatment of idiopathic respiratory distress syndrome. J Pediatr. 1967; 71: 243-6.

136. Fournier JA, Cortacero JA, Turá A, Hernández-Aparicio C, Granado C, Vallejo J. Effects of intracoronary injection of ergonovine on angiographic normal coronary arteries: study of 108 consecutive patients. Clin Cardiol. 1989; 12: 561-8.

137. Isogai $\mathrm{T}$, Yasunaga $\mathrm{H}$, Matsui $\mathrm{H}$, Tanaka $\mathrm{H}$, Ueda $\mathrm{T}$, Horiguchi $\mathrm{H}$, et al. Serious cardiac complications in coronary spasm provocation tests using acetylcholine or ergonovine: analysis of 21512 patients from the diagnosis procedure combination database in Japan. Clin Cardiol. 2015; 38: 171-7.

138. Khan IA, Mehta NJ. Initial historical descriptions of the angina pectoris. J Emerg Med. 2002; 22: 295-8.

139. Barold SS. Willem Einthoven and the birth of clinical electrocardiography a hundred years ago. Card Electrophysiol Rev. 2003; 7: 99-104.

140. Caralis DG, Deligonul U, Kern MJ, Cohen JD. Smoking is a risk factor for coronary spasm in young women. Circulation. 1992; 85: 905-9.

141. Sugiishi M, Takatsu F. Cigarette smoking is a major risk factor for coronary spasm. Circulation. 1993; 87: 76-9.

142. Hung MJ, Cherng WJ, Yang NI, Cheng CW, Li LF. Relation of high-sensitivity C-reactive protein level with coronary vasospastic angina pectoris in patients without hemodynamically significant coronary artery disease. Am J Cardiol. 2005; 96: 1484-90.

143.Song JK, Park SW, Kang DH, Hong MK, Kim JJ, Lee CW, et al. Safety and clinical impact of ergonovine stress echocardiography for diagnosis of coronary vasospasm. J Am Coll Cardiol. 2000; 35: 1850-6. 